\title{
Análise da presença da atividade da enzima alfa-amilase salivar em cães
}

\author{
Anne Karoline Mendes da Silva ${ }^{1 *}$; Natan Dias de Oliveira²; Elber Gomes Sousa ${ }^{3}$; Valéria Magro Octaviano \\ Bernis $^{4}$; Walter Octaviano Bernis Filho ${ }^{5}$
}

DOI: https://doi.org/10.35699/2447-6218.2020.25948

\begin{abstract}
Resumo
A alfa-amilase salivar é uma enzima unida ao cálcio que inicia a digestão de carboidratos tanto na cavidade oral como no vestíbulo da boca. Em animais, a alfa-amilase é secretada pelo tecido pancreático de todos os vertebrados e pela glândula salivar de alguns, entretanto, estudos sobre a presença da atividade da alfa-amilase na saliva de cães são escassos e contraditórios entre literaturas. Diante isso, o objetivo dessa pesquisa foi identificar a presença da atividade da enzima alfa-amilase salivar em cães. O protocolo usado para a determinação da enzima foi o descrito no kit colorimétrico específico e adaptado, sendo utilizado como base o método colorimétrico. Nesta metodologia, foi utilizado um kit de reagentes para determinação da atividade da amilase, onde a amostra de saliva foi incubada com o substrato amido e aquecida em temperatura de $38,9^{\circ} \mathrm{C}$, para simular a temperatura média do corpo de um cão. Pela adição da solução iodada, o amido não hidrolisado adquire coloração azul que diminui proporcionalmente à atividade enzimática, sendo comparado com um controle. Com os resultados obtidos dessa pesquisa, é possível concluir que, ao realizar a análise laboratorial das amostras colhidas, foi possível observar que não há presença significativa da alfa-amilase na saliva de cães que seja capaz de hidrolisar o amido.
\end{abstract}

Palavras-chave: Amido. Atividade enzimática. Saliva.

\section{Analysis of the presence of activity salivary alpha-amylase enzyme in dogs}

\begin{abstract}
Alpha-amylase is an enzyme united to calcium that initiates the digestion of carbohydrates in the oral cavity as well as in oral vestibule. In animals, alpha-amylase is secreted by the pancreatic tissue of all vertebrates and by the salivary glands of some. However, it is observed that studies on the presence of alpha-amylase activity in the saliva of dogs are scarce and contradictory between literatures. Accordingly, the aim of this investigation was to identify the presence of alpha-amylase enzyme in dogs. The protocol used to determine the enzyme was described in the specific colorimetric kit and adapted, being used as a basis the modified colorimetric. In this methodology, a reagent kit was used to determine amylase activity, where the saliva sample was incubated with starch substrate and heated to a temperature of $38,9^{\circ} \mathrm{C}$, to simulate a dogs average body temperature. By adding the iodine solution, the non-hydrolyzed starch acquires a blue color that decreases proportionally to the enzymatic activity, being compared with a control. With the results obtained from this research, it is possible to conclude that, when performing the laboratory analysis
\end{abstract}

${ }^{1}$ Instituto Federal do Norte de Minas Gerais. Salinas, MG. Brasil.

https://orcid.org/0000-0002-9494-1500

${ }^{2}$ Instituto Federal do Norte de Minas Gerais. Salinas, MG. Brasil.

https://orcid.org/0000-0001-5446-6744

${ }^{3}$ Secretaria de Saúde, Setor de Vigilância Epidemiológica, Canil Municipal. Salinas, MG. Brasil.

https://orcid.org/0000-0003-1296-2904

${ }^{4}$ Instituto Federal do Norte de Minas Gerais. Salinas, MG. Brasil.

https://orcid.org/0000-0001-8248-160X

${ }^{5}$ Instituto Federal do Norte de Minas Gerais. Salinas, MG. Brasil.

https://orcid.org/0000-0001-6553-6808

*Autor para correspondência: annemendes300@gmail.com

Recebido para publicação em 22 de Outubro de 2020. Aceito para publicação 25 de Dezembro de 2020.

e-ISSN: 2447-6218 / ISSN: 2447-6218. Atribuição CC BY. 
of the samples collected, it was possible to observe that there is no significant presence of alpha-amylase in the saliva of dogs that is capable of hydrolyzing starch.

Keywords: Enzymatic activity. Saliva. Starch.

\section{Introdução}

Durante o processo de domesticação dos animais, quando sua alimentação passou a ser controlada por homens, eles tiveram várias funções, desde fonte de alimento próxima ao homem, proteção contra outros animais, caça a pragas e atualmente considerados membros da família (Ogoshi, et al. 2015).

Com essa proximidade, com o aumento de produção de rações no país e devido à melhora do poder aquisitivo de proprietários, cães e gatos, passaram a obter alimentos mais sofisticados do que os que eram oferecidos anteriormente, havendo uma importante modificação na sua alimentação nas últimas décadas. Com isso, estudos referentes à digestão alavancaram, desde pesquisas referentes à ingestão de alimentos até a sua eliminação.

Dentre os nutrientes necessário que estão na alimentação desses animais, podemos notar que os carboidratos estão presentes em grandes quantidades em alimentos secos e semiúmidos para gatos e, principalmente para cães, tornando-o o princípio nutricional em maior quantidade na maioria dos alimentos secos para essas espécies (NATIONAL RESEARCH COUNCIL, 2006).

Embora não seja um nutriente essencial, os carboidratos são bem utilizados e digeridos nessas espécies, fornecendo uma fonte útil de energia e glicose. Na dieta dos cães, a fonte energética com base nos carboidratos pode reduzir a necessidade da proteína (Brown, 2009).

Sendo assim, é importante que haja um bom aproveitamento dos carboidratos pelos animais, e, segundo Moriel et al., (2010), o processo de quebra dessas grandes moléculas se inicia na boca com a mastigação, onde o acesso às enzimas salivares facilita sua digestão.

Dentre as enzimas estudadas no processo digestivo dos carboidratos, podemos pontuar a alfa-amilase salivar e a amilase pancreática. A alfa-amilase salivar, era conhecida antigamente como ptialina e é uma enzima que pode começar a clivar as ligações alfa-1,4 glicosídicas entre as moléculas de glicose no amido (REECE, 2017), porém, observa-se em animais que estudos sobre a presença da alfa-amilase na saliva de cães são escassos e contrários entre literaturas.

Nos animais onívoros, como ratos e porcos é citada a presença dessa enzima que digere amido (KLEIN, 2014). Nos animais carnívoros, como cães e gatos é citada, mas como ausente (Júnior; Lima; Saad, 2006). Existem opiniões divergentes quanto a presença ou ausência da enzima. Na citação de Reece (2017), descreve a presença da enzima alfa-amilase na saliva de cães e gatos.

Diante dos questionamentos e divergências na literatura sobre a presença da atividade da enzima alfa-amilase na saliva de cães, torna-se importante o desenvolvimento de pesquisas que esclareçam essa dúvida. Dessa forma, com os resultados desse trabalho, objetivou-se identificar a presença da atividade da enzima alfa-amilase salivar em cães, tornando este, um estudo com potencial para o conhecimento futuro relacionado à digestão de alguns animais monogástricos, como a melhora no balanceamento e composição de rações incluindo carboidratos.

\section{Material e métodos}

\section{Colheita de amostras:}

Para este estudo foram analisadas amostras de saliva oriundas de animais do Canil Municipal de Salinas-MG. O protocolo experimental desse trabalho foi aprovado pela Comissão de Ética na Utilização dos Animais (CEUA) do Instituto Federal do Norte de Minas Gerais sob o protocolo de número $07 / 2020$.

Foram colhidas onze amostras de cães sem raça definida, dos quais cinco eram machos e seis eram fêmeas. Os animais recebiam diariamente ração comercial e água à vontade. Foi realizada a correta contenção física dos animais, e com o auxílio de luvas e swab (zaragatoa), as amostras foram colhidas do vestíbulo da boca dos cães (todas simultaneamente no período da manhã) (Figura 1). Fichas com as identificações do animal, sexo e tipo de alimentação foram preenchidas (Tabela 1).

Em seguida, o swab foi inserido em microtubo tipo Eppendorf (tubo de microcentrífuga) para depositar a saliva. Os microtubos haviam sido anteriormente identificados e colocados $2 \mathrm{~mL}$ de solução $\mathrm{NaCl}$ 0,9\%. Os swabs e luvas utilizadas foram descartados e todo o material coletado foi acondicionado em caixa de isopor com gelo, para serem conduzidos ao laboratório e armazenados em congelador de geladeira e mantidos congelados $\left(-10^{\circ} \mathrm{C}\right)$ para posterior determinação da presença da atividade da enzima alfa-amilase salivar.

\section{Análise laboratorial:}

As análises foram feitas 24 horas após a coleta, sendo conduzidas em laboratório do Complexo de Atendimento Clínico Veterinário do Instituto Federal do Norte 
Análise da presença da atividade da enzima alfa-amilase salivar em cães

de Minas Gerais (IFNMG) - Campus Salinas, localizado na Fazenda Varginha, Rodovia MG-404, Km 02, Salinas-MG.
Os microtubos do tipo Eppendorf foram descongelados em temperatura ambiente.

Figura 1 - Colheita de saliva através de $s w a b$ (zaragatoa) no vestíbulo oral dos cães

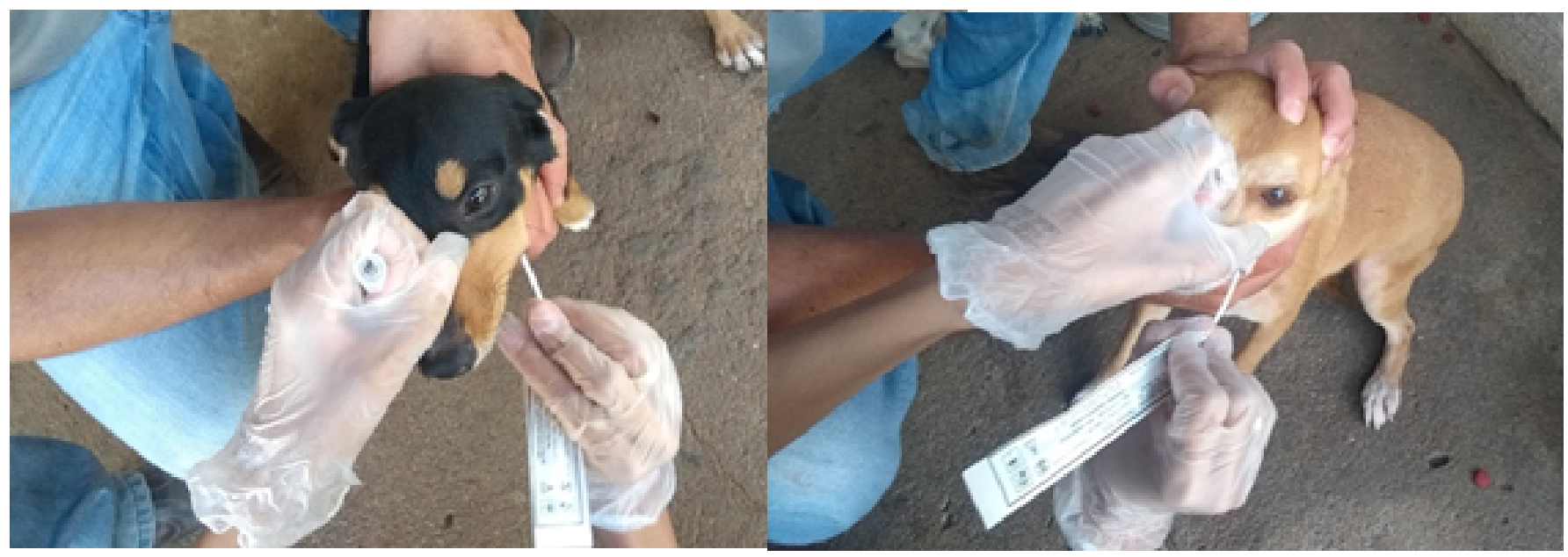

Tabela 1 - Identificação dos animais que foram coletadas as amostras

\begin{tabular}{llll}
\hline Cão/amostra & Identificação & Sexo & Alimentação \\
C1 & Baia 08-H & Macho & Ração comercial \\
C2 & Baia 16-P & Fêmea & Ração comercial \\
C3 & Baia 16-P & Fêmea & Ração comercial \\
C4 & Baia 16-P & Fêmea & Ração comercial \\
C5 & Baia 15-O & Macho & Ração comercial \\
C6 & Baia 15-O & Fêmea & Ração comercial \\
C7 & Baia 15-O & Fêmea & Ração comercial \\
C8 & Baia 13-M & Macho & Ração comercial \\
C9 & Baia 13-M & Macho & Ração comercial \\
C10 & Baia 04-D & Fêmea & Ração comercial \\
C11 & Baia 11-K & Macho & Ração comercial \\
\hline
\end{tabular}

O protocolo usado foi o descrito no kit colorimétrico específico (Amilase Colorimétrica K003, Bioclin, Quibasa Química Básica Ltda ${ }^{\circledR}$, Belo Horizonte, MG, Brasil) e adaptado, sendo utilizado como base o método colorimétrico modificado proposto por Caraway (1959), onde a amostra de saliva é incubada com o substrato amido (Reagente № 1) e aquecida em temperatura de $38,9^{\circ} \mathrm{C}$, para simular a temperatura média do corpo de um cão. Pela adição da solução iodada (Reagente № 2), o amido ainda não hidrolisado, adquire coloração azul que diminui proporcionalmente à atividade enzimática, sendo comparado com um controle.

A saliva humana possui constante atividade da enzima digestiva alfa-amilase (GUYTON; HALL, 2011). Foi realizado um teste inicial com saliva humana, seguindo detalhadamente o método inicial, validando a técnica empregada com o aspecto de saliva reagente, como demonstra a figura 3.

Os tubos do tipo Falcon foram separados e identificados. Também foi adicionado um tubo controle. Com base nas instruções do kit colorimétrico, foram distribuídos 0,5 mL do reagente № 1 em cada tubo, que foram mantidos por dois minutos em banho-maria à $38,9^{\circ} \mathrm{C}$. Ao serem retirados do banho-maria, foram adicionados 10 $\mu \mathrm{L}$ de cada amostra em cada tubo. O controle não obteve nenhuma adição. Em seguida foram homogeneizados e mantidos em banho-maria por sete minutos e trinta segundos a $38,9^{\circ} \mathrm{C}$ (Figura 2 ).

A análise da presença da atividade da enzima alfa-amilase salivar foi feita mediante a retirada dos tubos e visualização macroscópica da coloração da amostra após adicionar 0,5 $\mathrm{mL}$ do reagente № 2 e homogeneizar. 
Figura 2 - Amostras em banho-maria

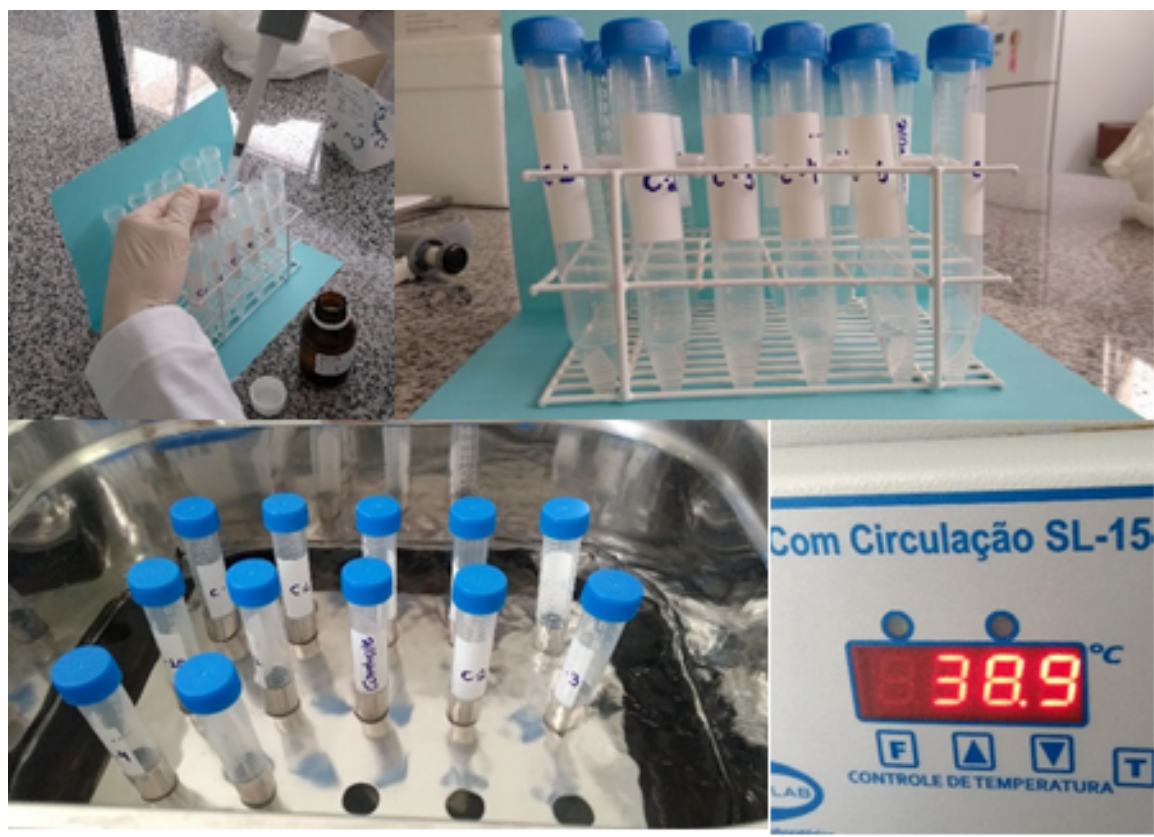

\section{Resultados e discussão}

A amostra de saliva humana empregada com o resultado colorimétrico, macroscópico, do amido hi- drolisado (a coloração da amostra salivar apresentou-se amarela) validou a técnica empregada e foi comparado com o controle (Figura 3 ).

Figura 3 - Amostra de saliva humana hidrolisada

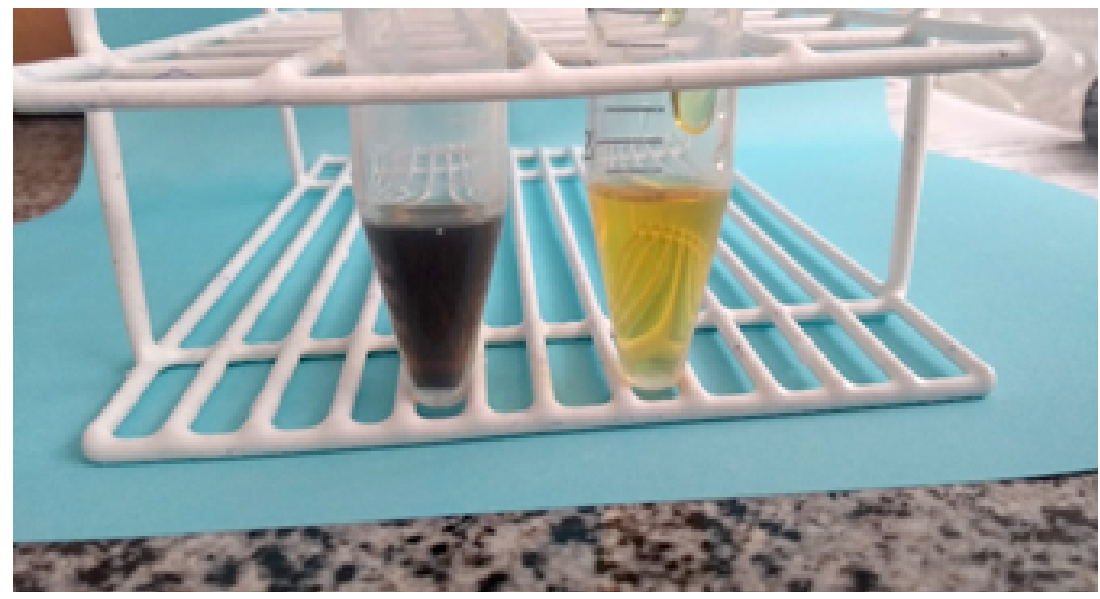

Ao realizar a análise laboratorial das amostras colhidas à campo dos onze animais, nenhuma apresentou resultados colorimétricos significativos da atividade enzimática. Ao adicionar o reagente № 2 , pode-se notar que as amostras apresentaram a mesma coloração que o controle e as cores eram proporcionais entre si, indicando assim a ausência da atividade da enzima alfa-amilase que tenha a capacidade de quebrar o amido. Isso pode ser evidenciado na figura 4.

O resultado obtido contradiz o que foi pontuado por Reece (2017) e Contreras-Aguilar et al., (2017), mas corrobora com outros autores (Júnior; Lima; Saad, 2006; Klein, 2014). Em trabalho realizado onde analisavam a composição de proteínas na saliva de cães, foi relatado também que a quantidade de alfa-amilase salivar era ausente ou muito baixa (Pasha, et al., 2018).

\section{Conclusão}

Com os resultados desse trabalho podemos concluir que ao realizar a análise laboratorial das amostras salivares, colhidas de cães do Canil Municipal de Salinas-MG, foi possível observar que não há presença significativa da alfa-amilase na saliva de cães que seja capaz de hidrolisar o amido.

\section{Aprovação do Comitê de Ética}

A pesquisa foi aprovada pelo Comitê de Ética no Uso de Animais (CEUA) do Instituto Federal do Norte de Minas Gerais sob número 07/2020. 
Figura 4 - Amostra com resultado negativo para a atividade da enzima.

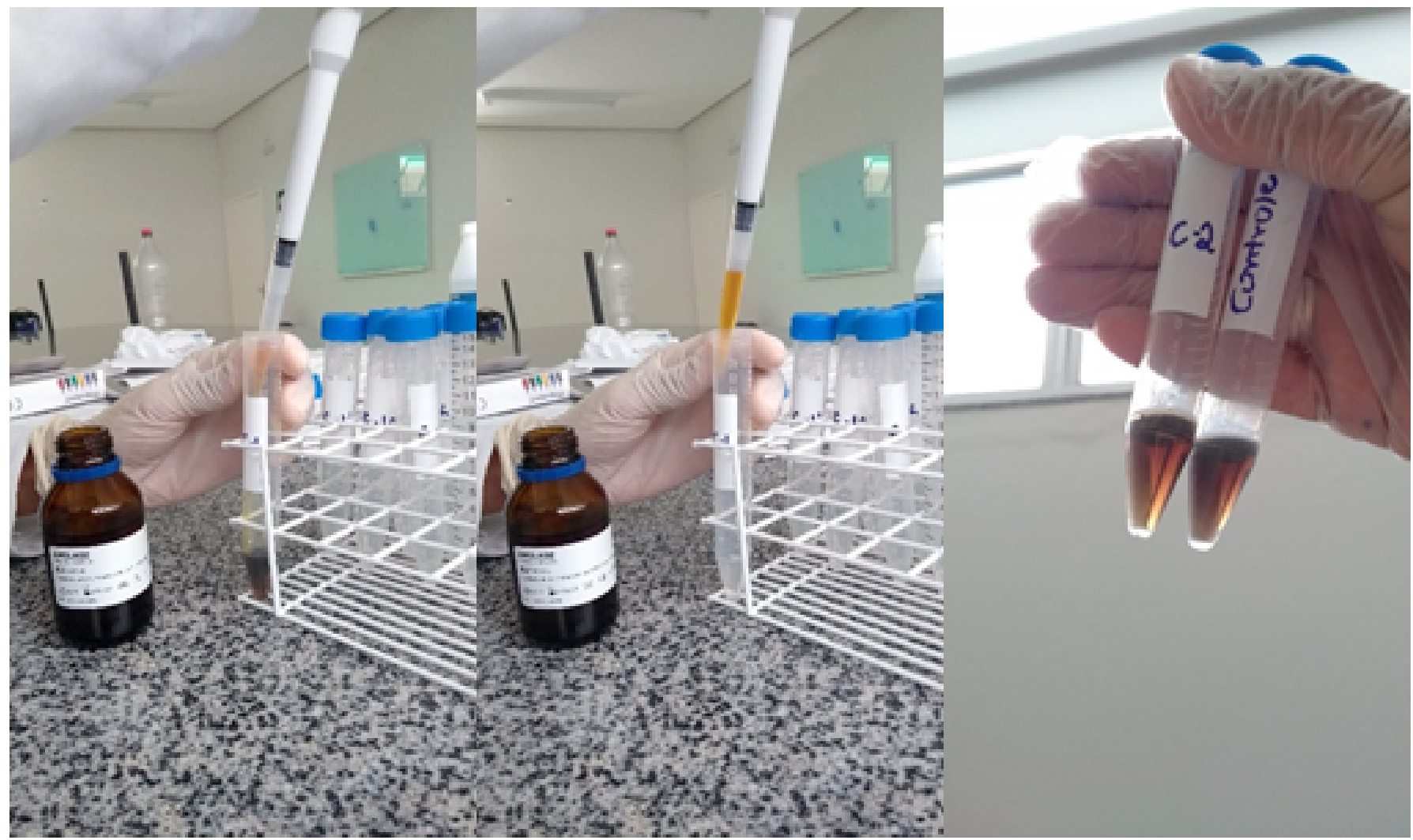

\section{Referências}

Brown, W. 2009. Companion animal nutrition. Applied Animal Nutrition 300/500, 30: 1-15. Disponível em: https://is.gd/sn2Fb7.

Caraway, W. T. 1959. A stable starch substrate for the determination of amylase in serum and other body fluids. American Journal of Clinical Pathology, 32: 97-99. Disponível em: https://is.gd/dBGUXI.

Contreras-Aguilar, M. D.; Tecles, F; Martínez-Subiela, S.; Escribano. D.; Bernal, L. J.; Cerón, J. J. 2017. Detection and measurement of alphaamylase in canine saliva and changes after an experimentally induced sympathetic activation. BMC Veterinary Research 13: 266. Doi: https:// doi.org/10.1186/s12917-017-1191-4.

Guyton, A. C.; Hall, J. E. 2011. Tratado de Fisiologia Médica. 12. ed. São Paulo: Elsevier.

Júnior, J. W. S.; Lima, L. M. S.; Saad, F. M. O. B. 2006. Fatores fisiológicos que interferem na digestão e aproveitamento do carboidrato em carnívoros domésticos. Revista Eletrônica Nutritime, 3: 331-338. Disponível em: https://is.gd/WBuXjC.
Klein, B. G. 2014. Cunningham tratado de fisiologia veterinária. 5. ed. Rio de Janeiro: Elsevier.

Moriel, P; Madureira, H. L.; Uwagoya, A. K. Y.; Wlian, L.; Pincinato, E. C. 2010. Influência do fumo na atividade da amilase salivar e na curva glicêmica. Revista de Nutrição, 23: 565-572. Doi: https://doi. org/10.1590/S1415-52732010000400007.

National Research Council. 2006. Nutrient requirements of dogs and cats. National Academy Press.

Ogoshi, R. C. S.; Reis, J. S.; Zangeronimo, M. G.; Saad, F. M. O. B. 2015. Conceitos básicos sobre nutrição e alimentação de cães e gatos. Ciência Animal, 25: 64-75. Disponível em: https://is.gd/XUOd7D.

Pasha, S.; Inui, T.; Chapple, I.; Harris, S.; Holcombe, L.; Grant, M. M. 2018. The saliva proteome of dogs: variations within and between breeds and between species. Proteomics, 18: 3-4. Doi: https://doi. org/10.1002/pmic.201700293.

Reece, W. O. 2017. Dukes: fisiologia dos animais domésticos. 13. ed. Rio de Janeiro: Guanabara Koogan. 